\title{
Electrophysiological study of young patients with exercise related paroxysms of palpitation: role of atropine and isoprenaline for initiation of supraventricular tachycardia
}

\author{
IKU TODA, TAKASHI KAWAHARA, YUJI MURAKAWA, AKIRA NOZAKI, \\ KIYOSHI KAWAKUBO, HIROSHI INOUE, TSUNEAKI SUGIMOTO
}

From the Second Department of Internal Medicine, University of Tokyo, Tokyo, Japan

SUMMARY Electrophysiological studies were performed in eight patients (four men and four women, mean (SD) age 24 (5) years with paroxysmal attacks of palpitation during or immediately after exercise. Five patients were competitive athletes at college. In two patients spontaneous supraventricular tachycardia during exercise was recorded by ambulatory electrocardiographic monitoring and in another it was induced by treadmill exercise testing. Two had dual atrioventricular nodal pathways, three had manifest atrioventricular accessory pathways, and three had concealed atrioventricular pathways. Programmed stimulation induced sustained supraventricular tachycardia in six patients-in two after intravenous injection of atropine sulphate (1 mg) and in four during infusion of isoprenaline $(0.01 \mu \mathrm{g} / \mathrm{kg} / \mathrm{min})$. In one patient, non-sustained atrioventricular nodal reentrant tachycardia was induced during isoprenaline infusion. In the remaining patient, who had dual atrioventricular nodal pathways, tachycardia was not inducible. AH block prevented maintenance of reentry in five patients. In five patients shortening of the effective refractory period of the atrioventricular node with atropine (one patient) and isoprenaline (four patients) caused sustained supraventricular tachycardia.

The present study indicates that treatment with atropine and isoprenaline may be an important factor in the initiation of supraventricular tachycardia in patients with exercise related paroxysms of palpitation.

It is widely accepted that well trained athletes tend to have bradycardia. ${ }^{12}$ Nevertheless, there are rare reports of exercise related supraventricular tachycardia. $^{3-8}$ Coelho et al reported various forms of tachycardia in young athletes, including five with paroxysmal supraventricular tachycardia. ${ }^{6}$ We report the electrophysiological findings in eight patients with exercise related paroxysmal palpitation.

\section{Patients and methods}

We studied eight patients (four men and four women,

Requests for reprints to Dr Iku Toda, The Second Department of Internal Medicine, University of Tokyo, 7-3-1, Hongo, Bunkyo-ku, Tokyo 113, Japan.

Accepted for publication 18 October 1988 mean (SD) age 24 (5) years) who were referred for electrophysiological study from October 1983 to 은 September 1987 because of repeated paroxysms of palpitation during or immediately after physical exercise or both. Five of eight patients were competitive athletes at college. History taking, physical of examination, 24 hour ambulatory electrocardiogra- $\tilde{N}$ phic monitoring, and a symptom limited exercise test on a treadmill or ergometer were performed in all 0 eight patients. We established that the paroxysms of palpitation were related to exercise, especially the intensity of exercise. The intensity of exercise was $\stackrel{\oplus}{\rightarrow}$ graded arbitrarily as follows: moderate $=$ higher level of exercise than daily activity (for example warming up exercises); strenuous = actual training $\stackrel{\mathbb{D}}{\circ}$ for competitive athletics (for example repeated trials of the 100 metre dash). 


\section{ELECTROPHYSIOLOGICAL STUDY}

Patients gave their informed consent to the electrophysiological study, which was performed while they were non-sedated and fasting. None of the patients had ever been treated with cardioactive drugs.

Three catheter electrodes (USCI 6F) were introduced percutaneously under fluoroscopic control into the femoral vein and positioned in the high right atrium, across the tricuspid valve for $\mathrm{His}$ bundle recording, and at the right ventricular apex. Left atrial potentials were recorded on an oesophageal lead (Medtronic 10F). ${ }^{9}$ Intracardiac potentials and the left atrial potential were filtered at 50$500 \mathrm{~Hz}$ and recorded simultaneously by leads I, aVF, and $\mathrm{V} 1$ on an ink jet recorder at paper speeds of 50 $100 \mathrm{~mm} / \mathrm{s}$. Analogue data were also recorded on magnetic tape for later analysis.

A digital programmable stimulator (Fukuda Denshi, BC02) was used to give programmed stimulation with $2 \mathrm{~ms}$ rectangular pulses that were 1.5 times diastolic threshold. Programmed stimulation was performed as follows: (a) extrastimulation (S2) was delivered from the high right atrium with a $10 \mathrm{~ms}$ reduction in the interval between stimuli every six sinus or atrial paced ( $\mathrm{S} 1$ ) beats (the basic paced cycle lengths ranged from 750 to $400 \mathrm{~ms}$ ); (b) incremental atrial pacing up to 200 beats/min; (c) extrastimulation (S2) delivered from the right ventricular apex after every six ventricular paced (S1) beats; and $(d)$ incremental right ventricular stimulation up to 200 beats/min. Because basic programmed stimulation did not induce supraventricular tachycardia in any of the eight patients, $1 \mathrm{mg}$ of atropine sulphate was injected intravenously and the study was repeated five minutes later. If induction of tachycardia did not follow injection of atropine, isoprenaline was infused at a rate of $0.01 \mu \mathrm{g} / \mathrm{kg} / \mathrm{min}$. The study was repeated five minutes after the start of isoprenaline infusion. Each episode of induced tachycardia was terminated by either rapid atrial pacing or extrastimulation.

The following definition $s^{10}$ were used:

(a) A1 and V1 are the atrial and ventricular electrograms of the sinus or basic drive beat; and A2 and V2, the atrial and ventricular electrograms of the extrastimulus.

(b) The effective refractory period of the atrium is the longest S1S2 interval that failed to result in atrial depolarisation.

(c) Effective refractory period of the atrioventricular node: the longest A1A2 interval in the His bundle electrogram that failed to propagate to the $\mathrm{His}$ bundle.

(d) The effctive refractory period of the accessory pathway was deemed to be the longest A1A2 interval that failed to propagate to the ventricle via the accessory pathway (anterograde) and the longest V1V2 interval that failed to propagate to the atrium via the accessory pathway (retrograde).

The diagnosis of atrioventricular nodal reentrant tachycardia and orthodromic atrioventricular reentrant tachycardia was based on established criteria. ${ }^{112}$ Premature atrial capture by ventricular extrastimulation and/or eccentric atrial activation during tachycardia were mandatory for diagnosis of atrioventricular reentrant tachycardia. A tachycardia was considered to be sustained if it lasted at least one minute and required stimulation for its termination. Tachycardia that lasted one minute or less was described as "non-sustained".

\section{Results}

Table 1 gives the clinical data. Patient 7 had pure posterior myocardial infarction possibly caused by Kawasaki's disease. Infarction was diagnosed by coronary angiography but the patient was symptom free during exercise except for paroxysms of palpita-

Table 1 Data on the patients and the results of electrophysiological study

\begin{tabular}{|c|c|c|c|c|c|c|c|c|c|}
\hline \multirow[b]{2}{*}{$\begin{array}{l}\text { Case } \\
\text { No }\end{array}$} & \multirow[b]{2}{*}{$\begin{array}{l}\text { Age (yr) } \\
\text { and sex }\end{array}$} & \multirow[b]{2}{*}{$\begin{array}{l}\text { History of } \\
\text { palpitation }\end{array}$} & \multicolumn{2}{|l|}{$P S V T$} & \multicolumn{3}{|c|}{$\begin{array}{l}\text { Induction of PSVT } \\
\text { by programmed stimulation }\end{array}$} & \multirow[b]{2}{*}{ Basis } & \multirow[b]{2}{*}{ Mechanism } \\
\hline & & & $\begin{array}{l}\text { Exercise } \\
\text { test }\end{array}$ & $\begin{array}{l}24 \text { hour } \\
\text { ECG } \\
\text { monitoring }\end{array}$ & Control & Atropine & $\begin{array}{l}\text { Isopren- } \\
\text { aline }\end{array}$ & & \\
\hline $\begin{array}{l}1 \\
2 \\
3 \\
4 \\
5 \\
6 \\
7 \\
8\end{array}$ & $\begin{array}{l}20 \mathrm{~F} \\
20 \mathrm{~F} \\
24 \mathrm{M} \\
34 \mathrm{~F} \\
23 \mathrm{M} \\
19 \mathrm{M} \\
33 \mathrm{M} \\
23 \mathrm{~F}\end{array}$ & $\begin{array}{l}1 \\
1 \\
2 \\
2 \\
2 \\
2 \\
2 \\
2\end{array}$ & $\begin{array}{l}- \\
- \\
- \\
- \\
- \\
+\end{array}$ & $\begin{array}{l}- \\
\overline{+} \\
+ \\
- \\
- \\
-\end{array}$ & $\begin{array}{l}\mathrm{Ae} \\
\overline{\mathrm{Ae}} \\
\overline{\mathrm{Ae}} \\
\mathrm{Ae} \\
- \\
-\end{array}$ & $\begin{array}{l}+ \\
+ \\
\pm \\
\pm \\
\mathrm{Ae} \\
\mathrm{Ae} \\
- \\
-\end{array}$ & $\begin{array}{l}+ \\
+ \\
+ \\
+ \\
\pm \\
-\end{array}$ & $\begin{array}{l}\text { WPW } \\
\text { C-WPW } \\
\text { C-WPW } \\
\text { WPW } \\
\text { WPW } \\
\text { C-WPW } \\
\text { DAVN } \\
\text { DAWN }\end{array}$ & $\begin{array}{l}\text { AVRT } \\
\text { AVRT } \\
\text { AVRT } \\
\text { AVRT } \\
\text { AVRT } \\
\text { AVRT } \\
\text { AVNRT } \\
\text { - }\end{array}$ \\
\hline
\end{tabular}

$\star$ Palpitation recurred during moderate exercise (1), and strenuous exercise (2). See text for details.

Ae, single atrial echo; AVRT, atrioventricular reentrant tachycardia; AVNRT, atrioventricular nodal reentrant tachycardia; DAVN, dual atrioventricular nodal pathways; ECG, electrocardiography; PSVT, paroxysmal supraventricular tachycardia; WPW, Wolff-ParkinsonWhite syndrome; C-WPW, concealed WPW; +, sustained PSVT; \pm , non-sustained PSVT; - , no PSVT. 
Start of PSVT

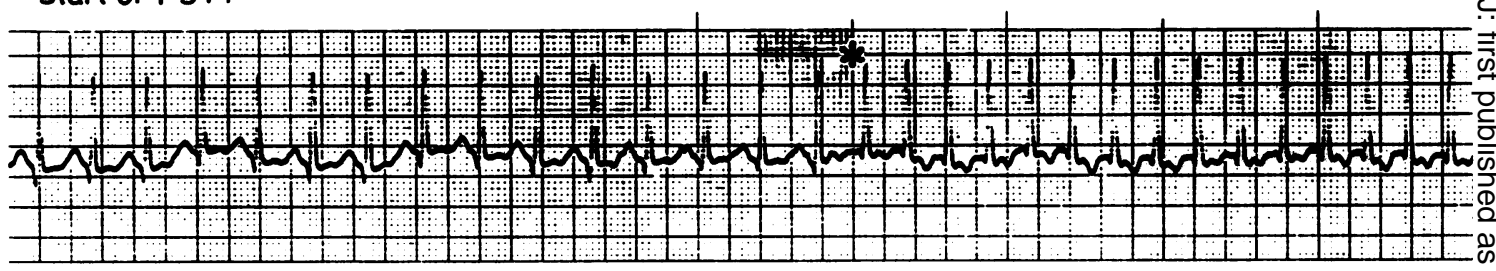

End of PSVT

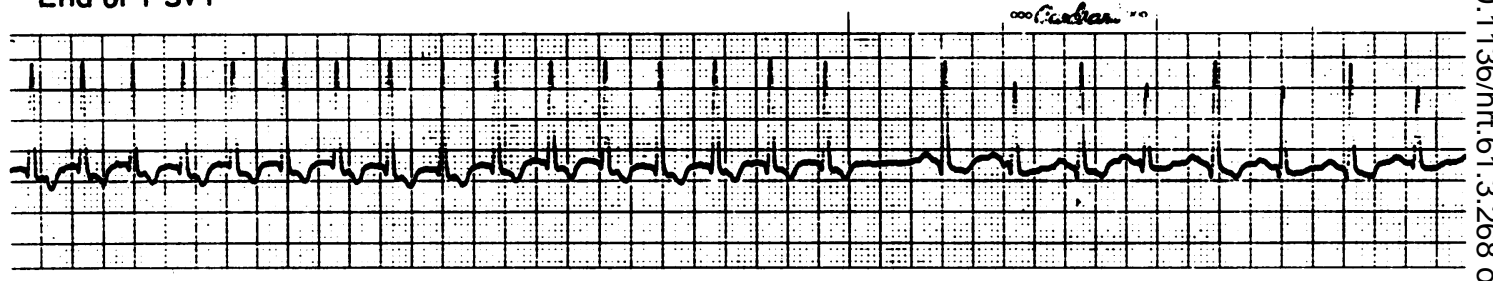

Fig 1 Spontaneous paroxysmal supraventricular tachycardia (PSVT) was recorded by 24 hour electrocardiographic monitoring (CM5 lead) in patient 4 while she was skiing. The asterisk indicates the start of paroxysmal supraventricular tachycardia. The heart rate was slowed by an atrioventricular block before the end of tachycardia. Strips are not continuous.

tion. Patients 1 and 2 had had episodes during moderate exercise, and the remaining six patients ( 3 to 8) had episodes only during and/or immediately after strenous exercise. Spontaneous paroxysmal supraventricular tachycardia was documented during an exercise test in one patient, and by 24 hour electrocardiographic monitoring in another two patients while they were exercising (fig 1, table 1). In these patients supraventricular tachycardia stopped spontaneously when exercise ended.

\section{ELECTROPHYSIOLOGICAL STUDY}

Atropine was given to all eight patients and isoprenaline to six patients. Table 2 shows the changes in effective refractory periods of the right atrium, atrioventricular node, and accessory pathway. There were dual atrioventricular nodal pathways in two patients (cases 7 and 8), a manifest accessory pathway 0 in three (cases 1, 4, and 5), and a concealed accessory. pathway in three (cases 2, 3, and 6). Because of atrioventricular nodal Wenckebach periodicity in the s control state and shortening of sinus cycle lengtho after injection of atropine or during isoprenalineô infusion, the effective refractory periods and induc- $\stackrel{\mathbb{Q}}{2}$ tion of tachycardia were measured at different basic $\overrightarrow{\vec{O}}$ cycle lengths in six of the eight patients (table 2). 3 Atropine shortened effective refractory periods of the atrioventricular node in all eight patients, although in? five of these the basic cycle lengths shortened after atropine injection (see Discussion). Changes in the effective refractory period of the accessory pathway? after atropine injection could be determined at the 3

Table 2 Electrophysiological data ( $m s$ )

\begin{tabular}{|c|c|c|c|c|c|c|c|c|c|c|c|c|c|c|c|}
\hline \multirow[b]{3}{*}{ Case No } & \multicolumn{5}{|c|}{ Control } & \multicolumn{5}{|c|}{ Atropine } & \multicolumn{5}{|c|}{ Isoprenaline } \\
\hline & \multirow[b]{2}{*}{$B C L$} & \multicolumn{4}{|l|}{$E R P$} & \multirow[b]{2}{*}{$B C L$} & \multicolumn{4}{|c|}{$E R P$} & \multirow[b]{2}{*}{$B C L$} & \multicolumn{4}{|l|}{$E R P$} \\
\hline & & $\overline{R A}$ & $A V N$ & $a-A P$ & $r-A P$ & & $\overline{R A}$ & $A V N$ & $a-A P$ & $r-A P$ & & $\overline{R A}$ & $A V N$ & $a-A P$ & $r-A P$ \\
\hline \multirow[t]{2}{*}{1} & $\begin{array}{l}600 \\
750\end{array}$ & $\begin{array}{l}320 \\
230\end{array}$ & $\begin{array}{l}380 \\
500\end{array}$ & 450 & $\begin{array}{r}300 \\
<280\end{array}$ & 600 & 210 & 300 & 420 & $<270$ & & * & $\star$ & $\star$ & $\star$ \\
\hline & 500 & $\star$ & $\mathbf{w}$ & - & $-{ }_{\star}^{200}$ & 500 & 200 & 310 & - & $<250$ & & * & * & $\star$ & $\star$ \\
\hline 3 & $\begin{array}{l}750 \\
600\end{array}$ & $\begin{array}{l}300 \\
\star\end{array}$ & $\begin{array}{l}360 \\
W\end{array}$ & - & 300 & 600 & 230 & 280 & - & 280 & 500 & 240 & 250 & - & $\star$ \\
\hline \multirow{2}{*}{$\begin{array}{l}4 \\
5 \\
6 \\
7\end{array}$} & $\begin{array}{c}500 \\
1000 t \\
600\end{array}$ & $\begin{array}{l}250 \\
280 \\
300\end{array}$ & $\begin{array}{r}>330 \\
<340 \\
370\end{array}$ & $\begin{array}{l}330 \\
400\end{array}$ & $\begin{array}{l}320 \\
\star \\
320\end{array}$ & $\begin{array}{l}500 \\
750 t \\
600\end{array}$ & $\begin{array}{l}170 \\
240 \\
260\end{array}$ & $\begin{array}{r}260 \\
<320 \\
310\end{array}$ & $\begin{array}{l}320 \\
390 \\
-\end{array}$ & $\begin{array}{l}310 \\
\star \\
310\end{array}$ & $\begin{array}{l}400 \\
450 t \\
600\end{array}$ & $\begin{array}{r}<250 \\
230 \\
270\end{array}$ & $\begin{array}{l}<250 \\
<270 \\
<270\end{array}$ & $\begin{array}{l}270 \\
280 \\
-\end{array}$ & $\begin{array}{l}\star \\
\star \\
300\end{array}$ \\
\hline & 750 & 250 & 510 & - & 年 & 750 & 250 & 300 & - & $=$ & & & - & & \\
\hline \multirow[t]{2}{*}{8} & 1000 & 290 & 490 & - & - & & & & & & 500 & $<200$ & $<250$ & - & - \\
\hline & 600 & & $w$ & - & - & 600 & 210 & 380 & - & - & 400 & 200 & 210 & - & - \\
\hline
\end{tabular}

\#Not determined. + Sinus cycle length. In patient 5 the interval between the atrial electrogram and stimulus artefact on high right atrial electrogram was expressed as the effective refractory period of the right atrium.

$A V N$, atrioventricular node; a-AP and r-AP, anterograde and retrograde conduction of accessory pathway respectively; BCL, basic paced $\mathbb{D}$ cycle length; ERP, effective refractory period; RA, right atrium; $W$, Wenckebach phenomenon. 
Control

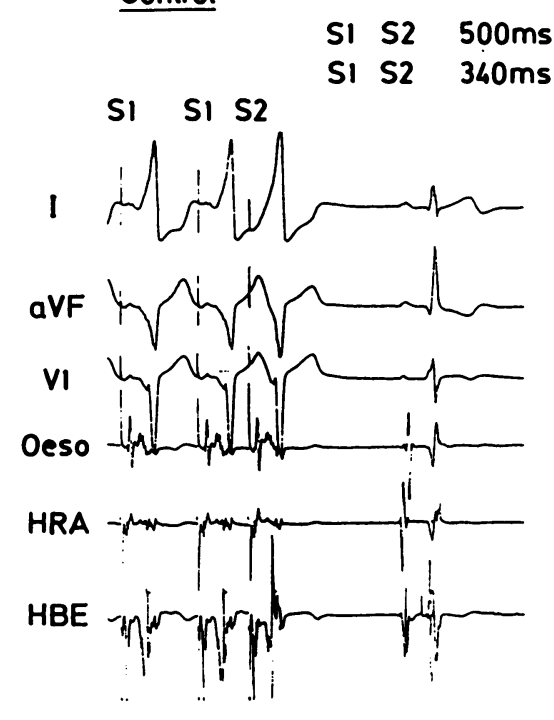

Atropine

S1 S1 S2

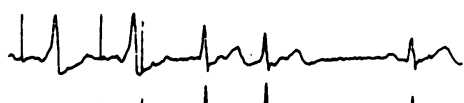

S1 $52500 \mathrm{~ms}$

S1 S2 $270 \mathrm{~ms}$
Atropine + isoprenaline

$\begin{array}{ll}\text { S1 S2 } & 400 \mathrm{~ms} \\ \text { S1 S2 } & 250 \mathrm{~ms}\end{array}$

S1 S1S2

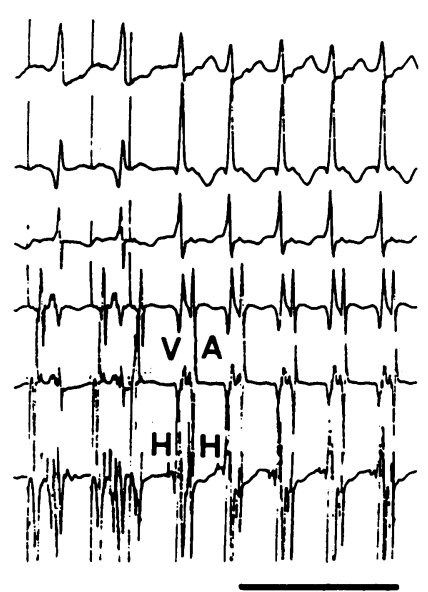

is

Fig 2 Electrophysiological study of patient 4 by electrocardiographic leads I, aVF, and V1; oesophageal lead (Oeso); high right atrial electrogram (HRA); and His bundle electrogram (HBE). During infusion of isoprenaline the spontaneous sinus cycle length shortened to $400 \mathrm{~ms}$. In the control state, premature atrial stimulation (S2) at a coupling interval (S1S2) of $340 \mathrm{~ms}$ did not induce a reciprocating beat, and $S 2$ at an S1S2 interval of $330 \mathrm{~ms}$ failed to result in atrial depolarisation. After atropine injection $S 2$ provoked two reciprocating beats, but atriohisian block prevented continuous reciprocation. During isoprenaline infusion, atrioventricular reentrant tachycardia was induced by an S1S2 interval of 250 ms. During tachycardia the oesophageal lead of the left atrial electrogram coincided with the lower atrial electrogram from the His bundle. Diagnosis of atrioventricular reentrant tachycardia was based on premature atrial capture by ventricular stimulation when the His bundle was refractory. $A$, atrial electrogram, $H$, His bundle potential, $V$, ventricular electrogram.

basic cycle length identical to control in only two patients ( 1 and 4 ). Isoprenaline shortened the sinus cycle from 1033 (140) ms to $523(81) \mathrm{ms}(\mathrm{p}<0.01)$. The effective refractory period of the atrioventricular node was shortened further by isoprenaline infusion in five patients, although basic pacing cycle lengths were shortened during infusion (see Discussion). Isoprenaline-induced changes in the effective refractory period of accessory pathway were determined at the basic cycle length identical to that during the control state in patient 6 only. Figure 2 shows a representative example of induction of supraventricular tachycardia by programmed stimulation in patient 4 whose spontaneous supraventricular tachycardia is shown in fig 1 . In the control state, supraventricular tachycardia was not induced in any patient. In four patients, single atrial echo which did not propagate to the ventricle because of atriohisian block was induced with programmed stimulation.

When the eight patients were given intravenous atropine injection, sustained supraventricular tachycardia was induced in two and non-sustained supraventricular tachycardia in another two (table 1). In the two patients (cases 5 and 6), single atrial echo was also induced but did not propagate to the ventricle after atropine injection. Isoprenaline was then infused in six patients in whom sustained supraventricular tachycardia was not induced after atropine injection. During isoprenaline infusion, sustained supraventricular tachycardia was induced in four patients and non-sustained supraventricular tachycardia in one patient. Supraventricular tachycardia was not sustained because of an atriohisian block after atropine injection in two patients and during isoprenaline infusion in one patient. In patient 8, tachycardia was not induced even during isoprenaline infusion. In summary, sustained reentry was facilitated by shortening of the effective refractory period of the atrioventricular node by atropine in one patient (case 1) and by isoprenaline in four (cases $3,4,5$, and 6 ).

\section{TREATMENT}

Patient 7 was advised against strenuous exercise and treated with oral verapamil (120 mg daily). The 
remaining seven patients were allowed to continue their athletic activities because their paroxysms of palpitation subsided as soon as exercise stopped.

\section{Discussion}

We found that atropine or isoprenaline was required to shorten the effective refractory period of the atrioventricular node for supraventricular tachycardia to be sustained in five of eight patients with paroxysms of palpitation related to exercise. Isoprenaline infusion was necessary to induce supraventricular tachycardia in those who had had episodes of palpitation during strenuous exercise. The basis for the arrhythmia included dual atrioventricular nodal pathways in two and manifest or concealed atrioventricular bypass in six of the eight patients.

ELECTROPHYSIOLOGICAL STUDIES OF EXERCISE RELATED SUPRAVENTRICULAR TACHYCARDIA

Supraventricular tachycardia is induced during exercise in from 0.1 to $2.8 \%$ of the population and it is less common than exercise related ventricular tachycardia or premature ventricular complexes. ${ }^{3-5}$ Electrophysiological data on cases of exercise related supraventricular tachycardia are limited. ${ }^{68}$ Coelho et al reported that four of five cases of exercise related supraventricular tachycardia had an atrioventricular accessory pathway and atrioventricular reentrant tachycardia. ${ }^{6}$ Shortening of the atrioventricular nodal refractory period by isoprenaline and atropine was necessary to sustain supraventricular tachycardia in one and two cases respectively. ${ }^{6}$ In two of five patients in Coelho et al's study supraventricular tachycardia occurred only during treadmill exercise at a high level. ${ }^{6}$

Akhtar et al reported on five cases of atrioventricular nodal reentrant tachycardia induced only by programmed stimulation after atropine injection. ${ }^{13}$ In three of five cases, the anterograde limb of the atrioventricular nodal reentrant pathway was refractory to the reciprocating impulse in the control state and atropine was required to reduce the refractory period of the atrioventricular node sufficiently to permit continuous reciprocation. Hariman et al reported a case of catecholamine dependent atrioventricular nodal reentrant tachycardia in which isoprenaline infusion led to the induction of tachycardia by enhancement of ventriculoatrial conduction. ${ }^{14}$ Isoprenaline facilitated the initiation of atrioventricular reentrant tachycardia by Brugada $e t$ $a l$ in 21 patients including 14 patients with exercise related circus movement tachycardia. ${ }^{15}$ Induction was allowed mainly by facilitation of anterograde conduction via the atrioventricular node. ${ }^{15}$

Our results resemble those of Brugada $e t a l^{15}$ and also those of Coelho et al, ${ }^{6}$ although we found nơ ventricular tachycardia. Manifest and concealed. atrioventricular accessory pathways were the com $\overrightarrow{\bar{c}}$ : mon basis for arrhythmia in the present study as ing that of Coelho et al. ${ }^{6}$ Because vagal activity is increased in athletes the effective refractory period of the atrioventricular node had to be shortened with atropine (one patient) or isoprenaline (four patients? in order to sustain supraventricular tachycardia in our study. Shortening of the basic cycle length mayb have been an additional mechanism facilitating the induction of sustained supraventricular tachycardiæw after atropine (one patient) and induction of non sustained supraventricular tachycardia during infusion of isoprenaline (one patient).

LIMITATIONS

The present study has several limitations. Firstly only three of eight patients showed spontaneous? arrhythmia. Therefore, the induced supraventricular tachycardia might not have been the cause of exercise related paroxysms of palpitation in the remaining five patients; none the less, four of them said that the palpitation that they experienced during inducepo tachycardia was similar to their exercise related palpitation. Secondly, comparison of effective refrac-0 tory periods of the right atrium, atrioventriculars node, and accessory pathway after drug injection was hampered by the different basic cycle lengths used $\frac{\mathrm{D}}{\mathrm{D}}$ Additionally, the presence of an accessory pathwaye prevented precise determination of the effective $\overrightarrow{0}$ refractory period of the atrioventricular node. Injec 3 tion of atropine or isoprenaline, however, facilitated conduction via the atrioventricular node. The refractory period of the atrioventricular node is known to lengthen as the basic cycle length gets shorter. $\frac{10}{7}$ A decrease of basic cycle length per se could shortenthe right atrial effective refractory period ${ }^{16}$ and might facilitate induction of supraventricular tachycardio by programmed stimulation. However, shortening of the effective refractory period of the atrioventricularo node with atropine or isoprenaline provided an important basis for continued reciprocation.은. Thirdly, a treadmill or ergometer exercise test provoked supraventricular tachycardia in only one patient. This low rate of provocation of tachycardia with an exercise test might be because exercise was N not as strenuous as that reported by Coelho et al. ${ }^{6} \mathrm{O}$ Finally, the mechanism of palpitation in patient 8 remained uncertain. We should have tested a higher dose of isoprenaline infusion.

CLINICAL IMPLICATIONS The present data and the results of Coelho et $a^{6}$ show that an exercise test rarely induces supraventriculard tachycardia in patients with exercise related 


\section{Exercise related paroxysmal ventricular tachycardia}

supraventricular tachycardia. Atropine and isoprenaline are needed to induce supraventricular tachycardia in those who under control conditions do not show this arrhythmia. We found that injections of atropine or isoprenaline were needed before supraventricular tachycardia could be induced by programmed stimulation in athletes with enhanced vagal activity.

\section{References}

1 Lichtman J, O'Rourke RA, Klein A, Karliner JS. Electrocardiogram of the athlete. Arch Intern Med 1973;132:763-70.

2 Talan DA, Bauernfeind RA, Ashley WW, Kanakis C, Rosen KM. Twenty-four hour continuous ECG recordings in long-distance runners. Chest 1982; 82:19-24.

3 McHenry PL, Fisch C, Jordan JW, Corya BR. Cardiac arrhythmias observed during maximal treadmill exercise testing in clinically normal man. Am J Cardiol 1972;29:331-6.

4 Murayama $M$, Shimomura $K$. Exercise and arrhythmias. Jpn Circ J 1979;43:247-56.

5 Podrid PJ, Graboys TB, Lampert S, Blatt C. Exercise stress testing for exposure of arrhythmias. Circulation 1987;75(suppl III):III-60-5.

6 Coelho A, Palileo E, Ashley W, et al. Tachyarrhythmias in young athletes. J Am Coll Cardiol 1986;7:237-43.

7 Strasberg B, Ashley WW, Wyndham CRC, et al. Treadmill exercise testing in the Wolff-Parkinson-
White syndrome. Am J Cardiol 1980;45:742-8.

8 Yeh SJ, Lin FC, Wu D. Exercise provocation of multiple reentrant tachycardias in a patient with permanent form of junctional tachycardia and intermittent ventricular preexcitation. Am Heart J 1986;112:1109-14.

9 Binkley PF, Bush CA, Fleishman BL, Leier CV. In vivo validation of the origin of the esophageal electrogram. J Am Coll Cardiol 1986;7:813-8.

10 Josephson ME, Seide SF, eds. Clinical cardiac electrophysiology. Techniques and interpretations. Philadelphia: Lea \& Febiger, 1979:41.

11 Akhtar $M$. Atrioventricular nodal reentrant tachycardia. Med Clin North Am 1984;68:819-30.

12 Prystowsky EN, Miles WM, Hegar JJ, Zipes DP. Preexcitation syndromes: mechanisms and management. Med Clin North Am 1984;68:831-94.

13 Akhtar M, Damato AN, Batsford WP, et al. Induction of atrioventricular nodal reentrant tachycardia after atropine. Report of five cases. Am J Cardiol 1975;36:286-91.

14 Hariman RJ, Gomes JAC, El-Sherif N. Catecholaminedependent atrioventricular nodal reentrant tachycardia. Circulation 1983;67:681-6.

15 Brugada P, Facchini M, Wellens HJJ. Effects of isoproterenol and amiodarone and the role of exercise in initiation of circus movement tachycardia in the accessory atrioventricular pathway. Am J Cardiol 1986;57:146-9.

16 Denes $P, W u$ D, Dhingra R, Pietras RJ, Rosen KM. The effects of cycle length on cardiac refractory periods in man. Circulation 1974;49:32-41. 